\title{
Four new species of Xenotarsonemus (Acari: Tarsonemidae) from Brazil
}

\author{
ANTONIO C. LOFEGO ${ }^{1}$, GILBERTO J. DE MORAES ${ }^{2} \&$ RONALD OCHOA ${ }^{3}$ \\ ${ }^{1}$ Depto. de Zoologia e Botânica, UNESP - Universidade Estadual Paulista, Campus de São José do Rio Preto, SP. Rua Cristóvão \\ Colombo, 2265, 15054-000 São José do Rio Preto, SP. E-mail: aclofego@ig.com.br \\ ${ }^{2}$ Depto. Entomologia, Fitopatologia e Zoologia Agrícola, ESALQ/Universidade de São Paulo, 13418-900 Piracicaba-SP, Brazil. \\ ${ }^{3}$ Systematic Entomology Laboratory, Agriculture Research Service, U.S. Department of Agriculture, Henry A. Wallace Beltsville Agri- \\ culture Center, Beltsville, MD 20705, USA.
}

\begin{abstract}
Four new species of Xenotarsonemus Beer (Acari, Tarsonemidae), X. brachytegula, X. pirassunungaensis, X. cerrado and $X$. spiniphorus, are described based on specimens collected from plants of the "Cerrado" vegetation in the State of São Paulo, Brazil.
\end{abstract}

Key words: Mite, taxonomy, Cerrado

\section{Introduction}

Fourteen species from different parts of the world are currently known in the genus Xenotarsonemus Beer, 1954 (Lin \& Zhang, 2002). Several authors (Arruda Filho \& Moraes, 2002; Zacarias \& Moraes, 2002; Feres et al., 2005; Buosi et al., 2006) have reported the presence of mites in this genus in Brazil, but in each case, the mites were not identified to the species level.

The objective of this paper is to describe four new species of Xenotarsonemus found on plants in southeastern Brazil, from "Cerrado" vegetation, which consists primarily of shrubs and short trees with twisted trunks and branches that cover approximately a quarter of the central part of the Brazilian territory. A large part of this area has been converted into agricultural land in the last few decades

\section{Material and methods}

Leaf samples of different plant species were collected from the Cerrado and taken to a laboratory where the tarsonemid mites were extracted and mounted for analysis.

The terminology used in this paper is the same used by Lindquist (1986). For each structure, the mean measurement is given in micrometers, followed in parentheses by the respective range. The following abbreviations are used for institutions where types were deposited: ESALQ/USP-Universidade de São Paulo, Escola Superior de Agricultura "Luiz de Queiroz", Departamento de Entomologia, Fitopatologia e Zoologia Agrícola, 13418-900 Piracicaba-SP, Brazil"; USNM-United States National Museum of Natural History, Smithsonian Institution, Washington DC 20560, USA: DZSJRP—Departamento de Zoologia e Botânica, Universidade Estadual Paulista (UNESP), 15054-000 São José do Rio Preto-SP, Brazil. 